\section{Assessment of nutritional status and its associated factors among people affected by human immune deficiency virus on antiretroviral therapy: A cross sectional study in Siltie zone, South Ethiopia}

\author{
Mewuba Shamil Saliya, ${ }^{1}$ Telake Azale, ${ }^{2}$ \\ Atinkut Alamirrew, ${ }^{2}$ \\ Dawit Jember Tesfaye ${ }^{3}$ \\ ${ }^{1}$ Maternal and Child Health Core \\ Process, South Nation, Nationalities and \\ People Regional State Health Bureau, \\ Hawassa; ${ }^{2}$ Institute of Public Health, \\ College of Medicine and Health \\ Sciences, University of Gondar, Gondar; \\ ${ }^{3}$ Department of Epidemiology, School of \\ Public Health, College of Medicine and \\ Health Sciences, Hawassa University, \\ Hawassa, Ethiopia
}

\begin{abstract}
\end{abstract}
Ethiopia is among the countries most affected by malnutrition and nutrition-related complications remain a challenging issue for Human Immunodeficiency Virus (HIV)infected patients and those involved in their care. The aim of this study was to assess nutritional status among HIV positive adults in South Ethiopia and assess risk factors for malnutrition in this population. Institution based cross sectional study was conducted among 428 HIV positive adults who are taking ART at 12 health centers, Silte zone, Ethiopia. Convenience sampling technique was used to select the study participants. Structured questionnaire and anthropometric measurements were used to collect data. Data were analyzed using SPSS version 20.0 software. Bivariate and multivariate analyses were used to identify predictors of malnutrition. P-value less than 0.05 were used as cut of point to declare statistical significance. Prevalence of chronic energy deficiency was $24.1 \%$. Food insecurity $[\mathrm{AOR}=0.35,95 \% \mathrm{CI}(0.21,0.62)]$, feeding $\leq 2$ meals/day $[\mathrm{AOR}=0.29,95 \% \mathrm{CI}$ $(0.29,0.13)]$, ambulatory functional status $[\mathrm{AOR}=3.4,95 \%$ CI $(1.67,6.98)]$ and absence of dietary counseling $[\mathrm{AOR}=1.7$, $95 \%$ CI $(1.05,2.78)]$ were found to be independent predictors of chronic energy deficiency among HIV positive adults. Prevalence of malnutrition was high among HIV infected adults who are on ART in the study area. Regular nutritional assessment of the patients and dietary counseling should be integrated with routine care for HIV/AIDS patients. HIV/AIDS prevention and control programs need to involve nutritionists or trained health care provider to integrate nutritional care services.

\section{Introduction}

The emergence of Human Immunodeficiency Virus (HIV) epidemic is one of the biggest public health challenges the world has seen in recent history. ${ }^{1}$ In the last three decades HIV has spread rapidly and affected all sectors of Ethiopian society. Recently, although the global incidence of HIV infection has stabilized and begun to decline in many countries with generalized epidemics, it varies widely between regions. Not all regions and countries fit the overall trends. Furthermore, the annual number of people newly infected with HIV has risen in the Middle East and North Africa from 43000 in 2001 to 59000 in 2010. Countries in the Sub Saharan Africa (SSA) are home to the majority of all people living with HIV in the world. ${ }^{1,2}$

In many developing countries, especially in SSA; HIV/AIDS and malnutrition are both prevalent than other parts of the world. ${ }^{3}$ A significant proportion of patients who require ART are malnourished because of low energy intake combined with increased energy demands due to HIV and other related infections, which is associated with increased resting energy expenditure. Food insecurity can lead to macronutrient and micronutrient deficiencies, which can affect both vertical and horizontal transmission of HIV, and contribute to immunologic decline; poor treatment outcome and increased morbidity and mortality among those already infected with the disease..$^{3-6}$

Ethiopia is the second most populous country in Africa with an estimated population of 83 million, of which over a third (32.7\%) live below the absolute poverty line and largely affected population by malnutrition and HIV/AIDS. Although the rate of new infections shows more than a $25 \%$ decline, it is still high and possibly expanding to newer population groups and geographic areas. Ethiopian Demographic and Health Survey 2011 data shows an overall prevalence of $1.5 \%$ among the general population and an estimate show as nearly 800,000 are living with HIV; more are orphaned..$^{7,8}$

There is no single defining pathophysiology to AIDS wasting. However, protein metabolism is abnormal in HIV-infected individuals and there are situations such as severe rapid weight loss, failure to respond to nutrition support and inability to achieve
Correspondence: Dawit Jember Tesfaye, School of Public Health, College of Medicine and Health Sciences, Hawassa University, P.O. Box 1560, Hawassa, Ethiopia.

Tel.: +251.912.17.31.29

E-mail: devanhijember@gmail.com

Key words: Nutritional status; Chronic energy deficiency; HIV positive; Antiretroviral therapy.

Acknowledgements: University of Gondor gave ethical clearance for the study. The authors appreciate the study participants for their cooperation in providing the necessary information. The authors acknowledge the local administrators and the community for their strong support during the study.

Conflict of interest: the authors declare that they have no competing interest.

Contributions: MS conceived the study and was involved in the design, coordination, field supervision and report writing. TA and AA were involved in providing advice during proposal preparation, report writing and reviewed the draft manuscript. DJ participated in data analysis and drafted the manuscript. All authors read and approved the manuscript.

Funding: none.

Received for publication: 25 October 2016. Revision received: 2 February 2017.

Accepted for publication: 26 April 2017.

This work is licensed under a Creative Commons Attribution 4.0 License (by-nc 4.0).

(C) Copyright M.S. Saliya et al., 2018

Licensee PAGEPress, Italy

Healthcare in Low-resource Settings 2018; 6:6361 doi:10.4081/hls.2018.6361

adequate energy intake, in which combined use of anabolic agents may be indicated. Micronutrient deficiencies, body weight loss, and wasting in advanced HIV disease are caused by a similar combination of decreased food intake or chronic food insecurity, catabolic state induced by Opportunistic Infections (OI) or malignancy, prolonged fever and depressive syndrome. Acute wasting tends to be associated with secondary infections (OI) and chronic wasting is associated with gastrointestinal disease. A decrease in the rate of HIV infection-related wasting has been reported in the era of highly active antiretroviral therapy. ${ }^{6,9,10}$ Adequate nutrition increases resistance to infection and disease, improves energy, and thus makes a person stronger and more productive and is also necessary to treat malnourished HIV patients. People who are infected with HIV require more 
nutrients to compensate for poor absorption, adverse drug effects, frequent diarrhea, nausea and recurrent opportunistic infections. ${ }^{11-13}$

Despite implementing different programs to control and prevent HIV/AIDS, new HIV infection is still widespread with subsequent progression to AIDS and death. Nutrition-related complications remain a challenging issue for HIV-infected patients and for those involved in their care. ${ }^{10,14,15}$

To improve the nutritional status of HIV positive individuals, designing and implementing proper intervention is vital. This requires sufficient evidence and context specific knowledge. In Ethiopia, however, there is little evidence regarding nutritional status of HIV positives. In addition, factors associated with malnutrition mainly food security status and dietary pattern and habit among peoples' living with HIV/AIDS receiving ART in the study area is far from complete. Therefore, this study aimed to assess the nutritional status and associated factors among HIV positive adults who are taking antiretroviral therapy at Silte zone, South Ethiopia.

\section{Materials and Methods}

\section{Study design and setting}

Institution based cross sectional study was conducted from September to October 2015 in 12 health centers of Siltie zone. The zone has 34 health centers and 1067 health workers, and providing health services for the total of 873,854 populations. Out of the total public health facilities, only 12 health centers are providing services for 1116 patients on pre ART and 653 patients on ART. Nutrition intervention activities include, 131 Outpatient therapeutic feeding programs, 13 Stabilization Centers (SC) to manage severely malnourished children including HIV infected children and 127 community based nutrition kebeles (smallest administrative unit) for early detection and prevention of malnutrition among children.

\section{Selection of study participants}

The study population comprised of HIV positive adults attending ART clinic for follow up visit at the health centers of Siltie zone. Single population proportion formula was used to calculate the sample size with the assumption of $25.5 \%$ prevalence of under nutrition among HIV infected adults, ${ }^{16}$ with $95 \%$ confidence level and $4 \%$ tolerable error. The sample size yield was 456. The calculated sample size was allocated to twelve health centers using proba- bility proportional to size. Convenience sampling technique was used to select the study participants. HIV positive adults' $\geq 18$ years of age and had base line or recent CD4 counts during the data collection period were included in the study. Patients who were seriously ill and unable to talk were excluded from the study.

\section{Data collection procedure}

Data were collected using structured questionnaire adapted from different literatures, ${ }^{16-23}$ and weight and height measurements. Medical records were reviewed for WHO clinical stage, CD4 count and opportunistic infections. The questionnaire contained sociodemographic and economic characteristics, HIV and nutritional history, medical and psychological condition, dietary habit and household food security status questions. The questionnaires was prepared in English and translated into Amharic language and back translated into English to check its consistency. The Amharic version was used for data collection.

\section{Measurements}

Participant height was measured by using standio-meter. The subjects were asked to remove their shoes, stand erect and look straight in horizontal plan. The shoulder blades, buttocks and the heel touch the standing measuring board. Height was recorded to the nearest $0.1 \mathrm{~cm}$. Weight was measured by using beam balance. The scale was checked at zero before each measurement. The subjects were asked to remove heavy clothes and weight measurement was recorded to the nearest $0.1 \mathrm{~kg}$. Five health officers and 12 nurses collected the data and three senior staffs supervised the data collection process.

Respondent nutritional status was classified as normal if the BMI was between 18.5 - $24.99 \mathrm{~kg} / \mathrm{m}^{2}$. Participants with severely low BMI $\left(<16.00 \mathrm{~kg} / \mathrm{m}^{2}\right)$, moderately low BMI $\left(16.00-16.99 \mathrm{~kg} / \mathrm{m}^{2}\right)$ and mildly low BMI 16.00 - $16.99 \mathrm{~kg} / \mathrm{m} 2$ ) were categorized as malnourished. Food security was assessed by using 6-item module during the last 30 days and the sum of affirmative responses to the six questions. The questions includes whether they did not have money to get food; afford to eat balanced meals; ever cut the size of meals or skip meals and how many days did this hap-

Table 1. Socio demographic characteristics and chronic energy deficiency status of HIV positive adults who are on ART, Siltie zone, south Ethiopia, 2015.

\begin{tabular}{|c|c|c|c|}
\hline & Yes N (\%) & $\begin{array}{l}\text { energy de } \\
\text { No } N(\%)\end{array}$ & Total N (\%) \\
\hline $\begin{array}{c}\text { Age (years) } \\
18-24 \\
25-34 \\
35-54 \\
55+\end{array}$ & $\begin{array}{c}4(3.9) \\
44(42.7) \\
52(50.5) \\
3(2.9)\end{array}$ & $\begin{array}{c}9(2.8) \\
123(37.8) \\
185(56.9) \\
8(2.5)\end{array}$ & $\begin{array}{c}13(3.0) \\
167(39.0) \\
237(55.4) \\
11(2.6)\end{array}$ \\
\hline $\begin{array}{l}\text { Sex } \\
\quad \text { Male } \\
\text { Female }\end{array}$ & $\begin{array}{l}40(38.8) \\
63(61.2)\end{array}$ & $\begin{array}{l}116(35.7) \\
209(64.3)\end{array}$ & $\begin{array}{l}156(36.4) \\
272(63.6)\end{array}$ \\
\hline $\begin{array}{l}\text { Residence } \\
\text { Urban } \\
\text { Rural }\end{array}$ & $\begin{array}{l}27(26.2) \\
76(73.8)\end{array}$ & $\begin{array}{c}72(22.2) \\
253(77.8)\end{array}$ & $\begin{array}{c}99(23.1) \\
329(76.9)\end{array}$ \\
\hline $\begin{array}{l}\text { Marital status } \\
\text { Married } \\
\text { Never married } \\
\text { Divorced/widowed }\end{array}$ & $\begin{array}{c}59(57.3) \\
4(3.9) \\
40(38.8)\end{array}$ & $\begin{array}{c}202(62.2) \\
18(5.5) \\
105(32.3)\end{array}$ & $\begin{array}{c}261(61.0) \\
22(5.1) \\
145(33.9) \\
\end{array}$ \\
\hline $\begin{array}{l}\text { Ethnic group } \\
\text { Siltie } \\
\text { Guraghe } \\
\text { Others }\end{array}$ & $\begin{array}{c}83(80.6) \\
17(16.5) \\
3(2.9)\end{array}$ & $\begin{array}{c}270(83.1) \\
37(11.4) \\
18(5.5)\end{array}$ & $\begin{array}{c}353(82.5) \\
54(12.6) \\
21(4.9)\end{array}$ \\
\hline $\begin{array}{l}\text { Occupation } \\
\text { Unemployed } \\
\text { Farmer } \\
\text { Self employed } \\
\text { Others }\end{array}$ & $\begin{array}{c}51(49.5) \\
36(35.0) \\
9(8.7) \\
7(6.8)\end{array}$ & $\begin{array}{c}145(44.6) \\
111(34.2) \\
55(16.9) \\
14(4.3)\end{array}$ & $\begin{array}{l}196(45.8) \\
147(34.3) \\
64(15.0) \\
21(4.9)\end{array}$ \\
\hline $\begin{array}{l}\text { Education } \\
\text { No education } \\
\text { Primary } \\
\text { Secondary+ }\end{array}$ & $\begin{array}{c}60(58.3) \\
39(37.9) \\
4(3.9) \\
\end{array}$ & $\begin{array}{c}191(58.8) \\
120(36.9) \\
14(4.3) \\
\end{array}$ & $\begin{array}{c}251(58.6) \\
159(37.1) \\
18(4.2) \\
\end{array}$ \\
\hline
\end{tabular}


pen; ever eat less than they felt because there wasn't enough money for food; every hungry but didn't eat. The food security status of respondents with raw score $0-1$ is coded as food secure and the two categories "low food security" (Raw score 2-4) and "very low food security" (Raw score 5-6) in combination are classified as food insecure. ${ }^{17}$ Wealth index is a composite measure of household's cumulative living standard. It is particularly important in countries that lack reliable data on income and expenditures. ${ }^{18}$ Respondents were ranked in to five wealth quintiles based on eight wealth indicator variables (electricity, ownership of agricultural land, ownership of electronics (TV, mobile, frig.), ownership of house and housing condition and toilet facilities. Lowest quintile was classified as poorest, second quintile as poor. Third quintile was defined as middle economic class. Fourth and Fifth quintile were classified as high and highest economic classification respectively.

\section{Data quality control and manage- ment}

The data collectors and supervisors were trained for two days on the objective, basic data collection skills and how to take anthropometric measurements. Pretesting of the instrument was made before the commencement of the actual data collection. The data collectors were supervised on daily basis for completeness and consistency of the filled questionnaire. The weight scale was checked against zero reading before weighing every participant.

\section{Data processing and Analysis}

Data were entered to Epi info version 3.5.1 and exported to SPSS version 16 for statistical analysis. Descriptive and summary statistics were used to reduce and present the data. Bivariate analysis was used primarily to assess association between dependent variable (malnutrition) and the independent variables (age, sex, residence, marital status, ethnic group, occupation, WHO clinical stage, CD4 count, opportunistic infection, functional status, HIV status disclosure to family, nutritional counseling, food security status, dietary frequency and wealth index). Then variables found to have p-value of $\leq 0.2$ were fitted in to multivariate logistic regression model to control the possible effect of confounders. Finally the variables which have significant association were identified on the basis of odd ratio (OR) with $95 \%$ confidence interval $(95 \%$ $\mathrm{CI})$ at $\mathrm{P}$ value $<0.05$.

\section{Ethical consideration}

Ethical clearance was granted by Institutional Review Board of Institute of
Public Health, College of Medicine and Health Science, University of Gondar and official letters was submitted to the SNNPR regional health bureau. The regional health bureau ethical review board approved the study and formally notified zonal health departments. Supervisors and data collectors were trained on confidentiality. The purpose and importance of the study was explained to the study participants and verbal informed consent was obtained from all participants before starting the interviews or taking body measurements and also they were informed about the freedom to withdraw their participation at any time of data collection. Confidentiality of the data were assured and kept anonymously; code number was assigned to the study participants without mentioning the name, the information that was collected during the study was kept in a file and locked with key. Participants identified as malnourished were given nutritional advice and support through comprehensive chronic care clinic.

\section{Results}

\section{Socio demographic characteristics}

Four hundred twenty eight clients participated in the study, making the response rate $93.8 \%$. The mean age of the respondents was $35.7(\mathrm{SD} \pm 8)$ years. The majority $272(63.6 \%)$ of the participants were female and more than two-third $329(76.9 \%)$ were living in rural areas. Three hundred fifty three $(82.5 \%)$ of the respondents belonged to Siltie ethnic group and $359(83.9 \%)$ of the respondents were Muslims. Housewives accounted for 196 (45.8\%) of the respondents. More than half $251(58.7 \%)$ of the participants were without formal education (Table 1).

\section{Medical and psychological condi- tions of participants}

Two hundred thirty five $(54.9 \%)$ of the respondents were graded to be at WHO HIV clinical stage I. Concerning CD4 count of the respondents $57(13.3 \%)$ had $<200$ cells/uL. One hundred and nine $(25.5 \%)$ of the respondents had opportunistic infection, of which tuberculosis was the leading ill-

Table 2. Past and present medical and psychological history of HIV infected adults who are on ART at the health centers of Siltie zone, South Ethiopia.

\begin{tabular}{lcc} 
& Number & $\%$ \\
WHO clinical stage & & \\
One & 235 & 54.9 \\
Two & 91 & 21.3 \\
Three & 96 & 22.4 \\
Four & 6 & 1.4 \\
CD4 count & & \\
s200 & 57 & 13.3 \\
$201-350$ & 124 & 29 \\
$351-500$ & 110 & 25.7 \\
$>500$ & 137 & 32 \\
\hline Opportunistic infections & & \\
Yes & 109 & 25.5 \\
No & 319 & 74.5 \\
Types of OI & & \\
Tuberculosis & 34 & 31.2 \\
Chronic diarrhea & 29 & 26.6 \\
Chronic cough & 14 & 12.8 \\
Oral/esophageal thrush & 11 & 10.1 \\
Prolonged fever & 10 & 9.2 \\
Others & 11 & 10.1 \\
\hline Functional status & & \\
Working & 388 & 90.6 \\
Ambulatory & 40 & 9.4 \\
Depressed & & \\
Yes & 29 & 93.2 \\
No & 399 & \\
\hline Chew chat & 49.6 \\
Yes & 374 & \\
No & & \\
\hline & & \\
\hline
\end{tabular}


ness which accounts for 34 (31.2\%) followed by chronic diarrhea $29(26.6 \%)$ and chronic cough 14 (12.8\%). Twenty nine $(6.8 \%)$ of the respondent had depression and $49(11.4 \%)$ of the respondents had history of chat chewing. Majority 400 (93.5\%) of the participants had disclosed their HIV status to their partner or family member (Table 2).

\section{Nutritional status and dietary habit of the respondents}

The prevalence of chronic energy deficiency (BMI $<18.518 .5 \mathrm{~kg} / \mathrm{m} 2$ ) was $24.1 \%$ [95\% CI $(20 \%, 28.1 \%)]$. The mean $( \pm \mathrm{SD})$ BMI of the respondents was $20.27( \pm 2.5)$. Out of the total respondents, $325(76 \%)$ had normal nutritional status. Severe, moderate, and mild chronic energy deficiency (CED) were detected on $10(2 \%), 24(6 \%)$ and 69 $(16 \%)$ respectively.

Age group $35-54$ (50.5\%), female $(61.1 \%)$, rural by residence $(73.7 \%)$, unemployed (49.5\%), married (57.3\%) and with no educational status $(58.2 \%)$ are the most affected groups (Table 1). Among the participants with normal BMI, 218 (50.9\%) had a habit eating kocho (false banana) $\geq$ once/day, $99(96.1 \%)$ and $98(95.2 \%)$ of the respondents had a habit to take meat and fruits $\leq$ once / week respectively (Table 3 ).

\section{Factors associated with nutritional status of HIV positive Adults}

Food secured HIV positive adults were less likely to be malnourished than patient with food insecurity $[\mathrm{AOR}=0.35,95 \% \mathrm{CI}$ $(0.21,0.62)]$. There was statistically significant association between malnutrition and frequency of feeding per day. Patient who ate $\geq 3$ meals /day were less likely to be malnourished when compared to those who ate $\leq 2$ meals /day $[\mathrm{AOR}=0.29,95 \% \mathrm{CI}$ $(0.29,0.13)]$. Patient who didn't get dietary counseling were 1.7 times more likely to develop malnutrition than who got the counseling $[\mathrm{AOR}=1.7,95 \%$ CI $(1.05$, 2.78)]. Patients with ambulatory functional status were 3.4 times more likely to be malnourished than patients with working functional status $[\mathrm{AOR}=3.4,95 \%$ CI $(1.67$, 6.98)] (Table 4).

\section{Discussion}

In many developing countries, especially in SSA; HIV/AIDS and malnutrition are both highly prevalent than other parts of the world. Food insecurity can lead to macronutrient and micronutrient deficiencies and contribute to immunologic decline, increased morbidity and mortality among those already infected with the disease. ${ }^{5}$
HIV/AIDS is associated with biological and social factors that affect the individual's ability to consume, utilize, and acquire food. ${ }^{19}$ Wasting in advanced HIV disease is caused by a similar combination of decreased food intake or chronic food insecurity, catabolic state induced by opportunistic infections or malignancy and functional status of the patient. ${ }^{20,21}$
In this study, high prevalence of Chronic Energy Deficiency was observed among HIV positive adults receiving ART. This prevalence was in line with the study conducted at Felege Hiwot hospital 25.5\% ${ }^{16}$ and Gondar University hospital $27.8 \% .{ }^{22}$ In contrary, the finding of this study was higher than the result reported from meta-analysis $(10.3 \%)$ conducted by pooling preva-

Table 3. Dietary habit and nutritional status of HIV positive adults who are on ART, Siltie zone, south Ethiopia, 2015.

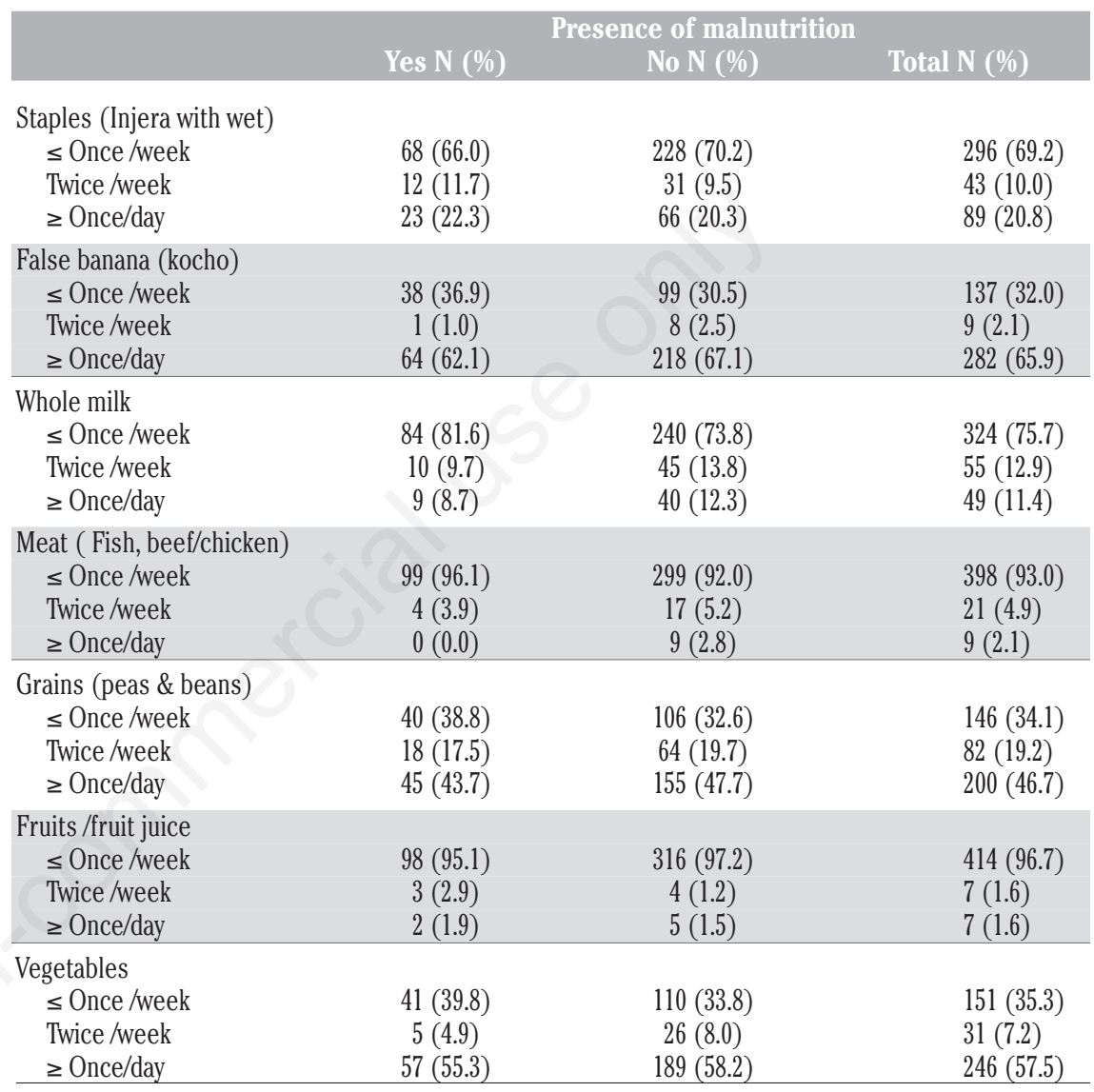

Table 4. Factors associated with malnutrition among HIV positive adults who are on ART, Siltie zone, South Ethiopia, 2015.

\begin{tabular}{lcccc} 
Predictors & Yes N(\%) & $\begin{array}{c}\text { Presence of malnutrition } \\
\text { No N(\%) }\end{array}$ & COR, 95\%CI & AOR, 95\%CI \\
$\begin{array}{l}\text { Food security } \\
\quad \text { Food secured }\end{array}$ & $21(12.9)$ & $142(87.1)$ & $0.33(0.19,0.56)$ & $0.35(0.21,0.62)$ \\
$\quad$ Food Insecure & $82(30.9)$ & $183(69.1)$ & 1 & 1 \\
Dietary counseling & & & & 1 \\
$\quad$ Yes & $57(19.9)$ & $230(80.1)$ & 1 & 1 \\
$\quad$ No & $46(32.6)$ & $95(63.4)$ & $1.9(1.24,3.10)$ & $1.7(1.05,2.78)$ \\
\hline
\end{tabular}

\begin{tabular}{lcccc}
\hline Functional status & & & & \\
$\quad$ Working & $85(31.3)$ & 303() & 1 & 1 \\
$\quad$ Ambulatory & 18() & 22() & $2.9(1.45,5.69)$ & $3.4(1.67,6.98)$ \\
Meal frequency & & & & \\
$\quad \leq 2 /$ day & $95(26.5)$ & $263(73.5)$ & 1 & 1 \\
$\geq 3$ day & $8(11.4)$ & $62(88.6)$ & $0.36(0.16,0.77)$ & $0.29(0.20,0.82)$ \\
\hline
\end{tabular}


lence estimate of 11 Sub-Saharan African countries between 2003 and 2006. ${ }^{23}$ This difference could be in the meta-analysis HIV infected women who are not on ART were included which could be undermining the prevalence since they are at lower risk of developing wasting than who are on ART. In a study done at Botswana, the prevalence of malnutrition among HIV infected adults was reported $30 \%$ which is higher than the finding of this study. Study from Miami, Florida. ${ }^{24}$ reported lower prevalence of CED (17.6\%) than the current study. This might be due to the difference in the general living condition and socio cultural characteristics of the countries.

HIV associated wasting has a strong association with food insecurity which can lead to decreased food intake. This study revealed that, food security status was associated with lower risk of malnutrition. In line with this, lower risk of malnutrition was observed among HIV positives with high meal frequency. These findings are consistent with the study conducted in Sub Saharan Africa which have shown malnutrition among HIV infected adult is common among population with food insecurity and HIV positive experience low diet quality and quantity. 5,6

Functional status of a patient is a proxy indicator of the underlying medical condition in which patients with deteriorated functional status could have a compromised health status which may result in increased losses of nutrient, decreased productivity and food intake which farther compromise the nutritional status of the patients. ${ }^{21,25}$ The finding of this study showed positive association between ambulatory functional status and chronically energy deficiency. This finding was inline with the study finding from south India where HIV infection affect the individual's ability to consume adequate quality and quantity of meals and thus can decrease the working capacity of HIV positive individuals. ${ }^{26}$

HIV positive adults especially those who are on ART are at higher risk of developing drug side effects and drug-food and nutrient interaction which can affects the individual's ability to consume and utilize the required nutrients. Nutrition counseling is necessary to decrease the effect of these problems on infected individuals. ${ }^{11-13}$ In this study, HIV positive adults who didn't get dietary counseling were 1.7 times more likely to develop malnutrition than those who got the dietary counseling. This finding is supported by the study conducted in South India which has shown macronutrient supplementation alone did not result in significantly increased weight gain without counselling. ${ }^{26}$
In the present study, opportunistic infection, WHO clinical stage, sex and income of the participants were not associated with CED. This could be attributed to the difference in study setting; Patient who present at referral hospital level are at advanced clinical stage and with low CD4 counts which makes the individuals more susceptible to HIV associated infections. Study findings from Felege Hiwot and Gondar University hospitals, North Ethiopia $^{16,22}$ showed that as there are $85.8 \%$ and $74 \%$ of the respondents were at clinical stage III and IV respectively.

\section{Conclusions}

The prevalence of chronic energy deficiency was high in the study area. HIV positive adults with food insecurity, ambulatory functional status, who feed $\leq 2$ meals /day and didn't get dietary counseling were more likely to be malnourished. Regular nutritional assessment of the patients and dietary counseling should be integrated with routine care for HIV/AIDS patients. HIV/AIDS prevention and control program need to involve nutritionist or trained health care providers to integrate nutritional care services. HIV related symptoms and other medical conditions should be treated as soon as possible to improve the functional status of patients. Developing income generating activities and other sectorial programs are required to improve and ensure food security and adequate meals intake of HIV positives. Further longitudinal study to understand the effect of CD4, WHO clinical staging disclosure status of patient and, depression on nutritional status of HIV positive adults is forwarded.

\section{References}

1. United Nations Program on HIV/AIDS. Report on the Global AIDS Epidemic, UNAIDS; 2010.

2. World Health Organization. Global HIV/AIDS response: epidemic update and health sector progress towards universal access: progress report; 2011.

3. World Health Organization. Nutrient requirements for people living with HIV/AIDS: Report of a technical consultation. Geneva: World Health Organization; 2003

4. Lisa K. Energy expenditure in HIV infection. Am J Clin Nutr 2011;94: 1677S-82S.

5. John R, Douglas C. Nutritional aspects of HIV-associated wasting in subSaharan Africa. Am J Clin Nutr
2010;91:1138S-42S.

6. Weiser S, Bangsberg D, Kegeles S, et al. Food Insecurity among Homeless and Marginally Housed Individuals Living with HIV/AIDS. AIDS Behav 2009; 13:841-8.

7. Federal Democratic Republic of Ethiopia. Country progress report; 2012.

8. International Central Statistical Agency and Ethiopia Demographic and Health Survey. Cent. Stat. Agency, Addis Ababa, Ethiopa. Calverton, Maryland, USA: ICF International; 2011.

9. Derek C. Clinical Trials for the Treatment of Secondary Wasting and Cachexia. J Nutr 1999;129:238S-42S.

10. Wanke C. Nutrition and HIV in the international setting. Nutrition Clin Care 2005;8:44-8.

11. De Pee S, Semba R. Role of nutrition in HIV infection: Review of evidence for more effective programming in resource-limited settings. Food \& Nutr Bull 2010;31:313S-44S.

12. Laurence A, Chantal U, Helena H, et al. Nutrition outcomes of HIV-infected malnourished adults treated with readyto-use therapeutic food in sub Saharan Africa. Food \& Nutr Bull 2010;31:287S-364S.

13. Federal Democratic Republic of Ethiopia, Federal HIV/AIDS Prevention and Control Office. Report on progress towards implementation of the UN Declaration of Commitment on HIV/AIDS; 2010.

14. Louise C, Kimberly A, Kenneth A, et al. HIV/AIDS, under nutrition, and Food Insecurity. Oxford J Med Clin Infect Dis 2009;49:1096-102.

15. Mangili A, Murman D, Zampini A, et al. Nutrition and HIV Infection: Review of Weight Loss and Wasting in the Era of Highly Active Antiretroviral Therapy. Clin Infect Dis 2006;42:83642.

16. Daniel M, Mazengia F, Birhan D. Nutritional status and associated factors among adult HIV/AIDS clients in Felege Hiwot referral hospital, Bhir Dar, Ethiopia. Sci J Public Health 2013;1:24-31.

17. Stephen J, Karil B, William L, Ronette $R$. The effectiveness of a short form of the household food security scale. Am J Public Health 1999;89:1231-4.

18. Rutstein S, Kiersten J. The DHS Wealth Index. DHS Comparative Reports No. 6. Calverton, Maryland, USA: ORC Macro; 2004.

19. Shalini D, Tulsi D, Ashish K. HIV and Malnutrition: Effects on Immune System. Clin Development Immunol 
2012;784740.

20. World Health Organization. Executive summary of a scientific review: an update, WHO Regional Consultation on Nutrition and HIV/AIDS. WHO; 2007.

21. Spiegelman D, Drain P, Mwiru R, et al. Predictors of weight loss after HAART initiation among HIV-infected adults. AIDS 2012;26:577-85.

22. Wasie B, Kebede Y, Yibrie A. Nutritional Status of Adult living with HIV/AIDS at the University of Gondar referral hospital, North West Ethiopia. Etiop J Health Biomed Sci 2010;3:3-14.

23. Olalekan A. Prevalence and pattern of HIV-related malnutrition among women in sub-Saharan Africa: a metaanalysis of demographic health surveys. BMC Public Health 2008;8:226.

24. Adriana C, Yang Z, Shenghan L, et al. HIV-Related Wasting in HIV-Infected Drug Users in the Era of Highly Active Antiretroviral Therapy. Clin Infect Dis 2005;41:1179-85.
25. Desta K. The pattern of immunologic and virologic responses to Highly Active Antiretroviral Treatment (HAART): Does success bring further challenges? Ethiop J Health Dev 2011;25:61-70.

26. Swaminathan S, Padmapriyadarsini C, Yoojin L, et al. Nutritional Supplementation in HIV-Infected Individuals. Clin Infect Dis 2010;51:517. 